\title{
The Role of Pedagogical and Subject Matter Knowledge in Preservice Art Teaching
}

\section{Jeanie Auseon}

\section{The Problem of Preservice Art Teachers' Limited Knowledge \\ Base}

According to research on teaching, strong evidence exists that many beginning teachers have limited knowledge about their own discipline (Anderson, 1988, Shulman, 1986, 1987). A teacher's professional knowledge affects all phases of instruction--lesson content and planning, implementation, assessment, and reflection. In the domain of art education, limited knowledge affects the teacher's representation of the field of art, the focus of inquiry and criticism, and the criteria and method for assessment. Art teacher understanding also affects how (or if) studio activities are used to reinforce lesson content. Teaching how to teach and learning how to teach is difficult. Aristotle believed that ultimate understanding rested on one's ability to transfer knowledge into teaching (cited in Shulman, 1986). Toward Civilization, a report on arts education (NEA, 1988) describes the importance of high standards of teaching in the arts by knowledgeable teachers trained in the disciplines and philosophy of the arts . . with a well developed "learner knowledge" and "teaching methodology" (p. 105). The fields of education and art education need more information on how art teacher knowledge is translated into art instruction as this in turn affects the knowledge their students will come to have about art.

\section{The Relationship of Teacher Knowledge and Art Teaching}

Current research on teaching describes a knowledge base of teachers and investigates how that knowledge affects lesson planning and instruction. Through research, several models of teacher knowledge have been developed (e.g., Elbas, 1983; Leinhardt and Smith, 1985; Shuiman, 1986, 1987, Wilson, Shulman \& Richert, 1987). These models were used as a foundation in the design of this study. Though differences exist between the number of sub-components identified in each of the models, there is a general agreement that four main categories of professional knowledge for teaching are: (1) general pedagogical knowledge, (2) subject matter knowledge, (3) pedagogical content knowledge, and (4) knowledge of context (Grossman, 1990, p. 5, see Figure 1).

The following operational definitions describe the three main categories of teacher knowledge used in this study. 
Figure 1. Model of Teacher Knowledge

Figure 1.1. Model of Teacher Knowledge

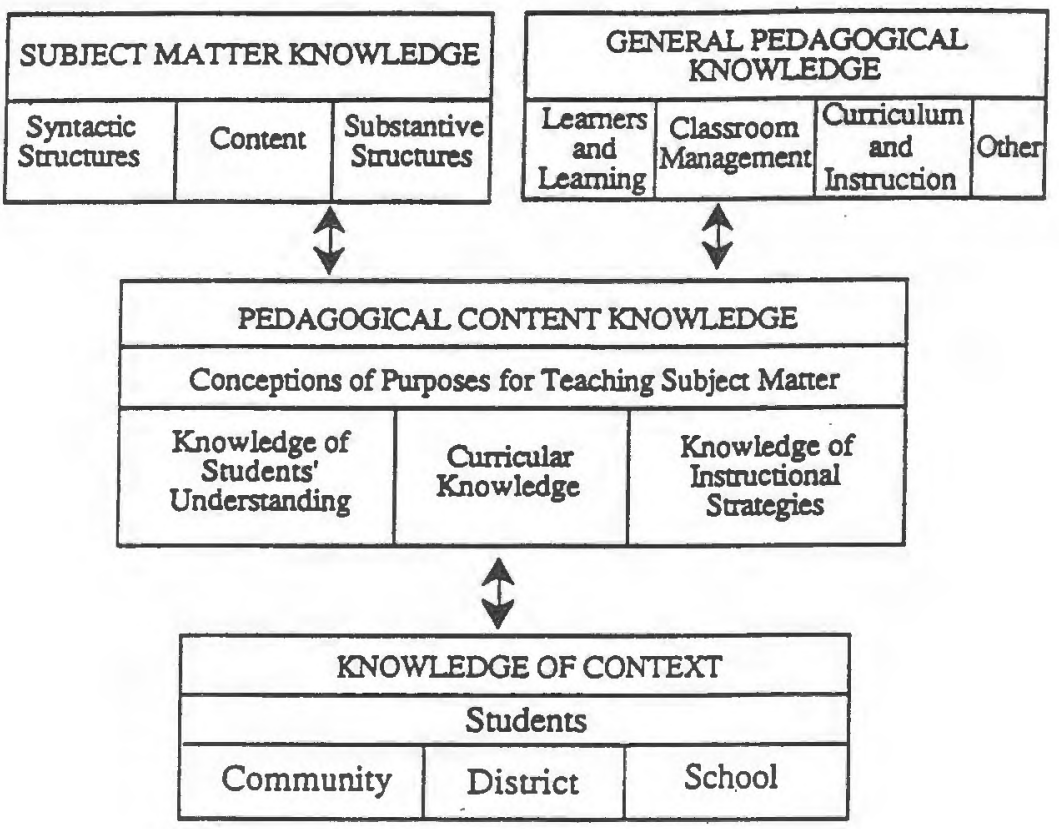

Grossman 1990 


\section{General Pedagogical Knowledge}

Research literature defines this as the knowledge of teaching and leaming theories, principles, and processes that cut across disciplines (Reynolds \& Strom, 1988). It is also the skill in th use of teaching methods and strategies that are not subject-specific (Gudmundsdottir, 1987, p. 4).

\section{Subject Matter Knowledge}

This is the teacher's understandings of the subject she/he teaches (Gudmundsdottir, 1987, p. 6). The depth and organization of this knowledge influences how teachers structure and teach lessons (Wilson \& Winberg, 1988). Dewey (1904) referred to the role of subject matter knowledge in teaching and suggested that scholarly knowledge of a discipline is different than the knowledge needed for teaching.

\section{Pedagogical Content Knowledge}

Findings from research centers (e.g., the Knowledge Growth in Teaching project at Stanford, and the Center for the Learning and Teaching of Elementary Subjects at Michigan State University) have clarified how subject matter knowledge and general pedagogical knowledge are transformed into pedagogical content knowledge.

Researchers have studied teachers at different professional levels during the process of lesson planning and teaching to analyze this transformation. A teacher's pedagogical content knowledge is described as the ability to:

1. understand the central topics, skills, and atitudes in a field

2. know what aspects of these topics will be interesting and/or difficult to understand for students

3. develop and/or select examples that best represent central ideas in a field

4. question students effectively about these topics (Shulman and Sykes, 1986, p. 6).

This study examines the organization, and utilization of pedagogical content knowledge by beginning art teachers. Because several 
sub-components of teacher knowledge are documented in teacher education literature, this study limits its examination to the variables of teacher understanding of learners' prior knowledge and teacher subject matter knowledge regarding key concepts. Cognitive research findings verify that teacher consideration of these factors might promote higher-order teaching and learning. Operation definitions of learners' prior knowledge and key concepts are as follows:

1. Learners' prior knowledge - All the accumulated knowledge, (including misunderstandings), skills and experiences a student currently possesses; what the student already knows about the material being studied (Koroscik, 1922).

2. Key concepts - The basic ideas that lie at the heart of a discipline and allow for rich connections (Prawat, 1989, p. 6).

In a report on professional education for teachers, Howsam, et. al., (1976) stated that "If the promise of the teaching profession is to be achieved, we must attend to the processes by which its knowledge base is developed and transmitted." Recent studies on teaching and learning have focused on teachers' roles, thoughts, actions, planning,thinking, decisionmaking, and identification of pedagogical principles and theories (Porter \& Brophy, 1988). Such studies explain how teachers learn to teach and describe how they teach as a result of what they have learned.

Understanding the impact of teacher knowledge is essential if education in general and art education specifically are to reshape teacher preparation as a means of improving the overall quality of art education in this country (Carnegie, 1986; Holmes Group, 1986; Shulman, 1986, 1987; Bellon, Bellon \& Blank, 1992).

\section{Research Questions}

Questions addressed in this study have already been examined in areas of education which study how their disciplines are best transformed into school subjects. These questions have been transposed to the field of art teacher education for the purposes of this study. To examine the effects of pedagogical and subject matter knowledge on preservice art teaching, and to fill a gap in existing teacher education research, this study addresses the following questions:

1. What understandings do preservice art teachers have about learners' prior knowledge in art instruction?

Marilyn Zurmuehlen's Working Papers In Art Education 1994-1995 
2. How does a knowledge of learners affect the planning and content of art instruction?

3. What do preservice art teachers select as key concepts in art instruction?

4. How do selected key concepts affect the content and process of art instruction?

5. How do preservice art teachers understand the role of studio in art instruction?

6. How does the understanding of the function of studio affect the planning and content of art instruction?

\section{Overview of Research Methods}

A study with three phases was designed to explore these questions. The phases sought to incorporate the six aspects of pedagogical reasoning and action identified at the Knowledge Growth in Teaching project at Stanford (Gudmundsdottir, 1987). Those are: (1) comprehension, (2) transformation, (3) instruction, (4) evaluation, (5) reflection, and (6) new comprehension (p. 5).

As previously mentioned, two sub-components of Grossman's (1990) model of teacher knowledge were selected as variables to be examined in each phase of this study. The variables are: (1) teacher understanding of the role of learners' prior knowledge, and (2) teachers' subject matter knowledge as represented by key concepts in art teaching.

The function of studio in art lesson planning as it pertains to these two variables will also be examined. The design, participants, materials and procedures for each of the three phases are discussed below.

\section{Phase One: Lesson Plan Critique}

This phase analyzes student ant teachers' comprehension and transformation of information into lesson plans. To examine student art teachers' understanding of the roles of learners' prior knowledge, key concepts, and studio in lesson planning, preservice teachers were asked to critique what they considered to be their most "successful" lesson plan from student teaching. They were given six questions to consider. 
Participants were four weeks into the sixteen weeks of student teaching when they were given this fifteen minute writing activity as part of the required coursework in their weekly Student Teaching Seminar. A critique form was provided on which they explained their understandings of their learners' prior knowledge, the key concepts selected for the lesson and overall unit, and the reasons they selected these key concepts. Participants were asked to describe any connections they made between the learners' prior knowledge and/or key concepts and the studio activity in this lesson plan. These critiques were analyzed as pre-test data. Three educational interventions occurred after this critique. These interventions were in the form of a workshop. After the workshop, a re-critique of this lesson plan (post-test data) was collected and is described in phase three.

The nineteen participants in the study were art education majors at Buffalo State College, Buffalo, New York. A weekly seminar and sixteen weeks of student teaching are part of the requirements for teaching certification by the College's Department of Art Education. All participants had completed the required methods and studio courses for art teaching certification; a few had additional studio experience as they were practicing artists or had an undergraduate degree in art and were obtaining art teaching certification. None of the participants had previous formal teaching experience, though a few had worked with learners in informal art education settings. Fourteen of the nineteen participants were female, nine were male.

\section{Phase Two: Workshop on Cognitive Teaching-Learning Research and Art Teaching}

Phase two focused on the aspects of instruction and evaluation. It occurred in the form of an educational workshop during a weekly Student Teaching Seminar. The workshop has three teaching-learning activities. For the first activity, participants observed a summarized, videotaped unit of art instruction. Participants observed an interview with the art teacher from the first video as the second activity. direct instruction on cognitive learning research that advocates the consideration of learners' prior knowledge and teaching with key concepts was the third activity in this workshop. The workshop lasted approximately two-and-one-half hours.

\section{Activity One: Participant Observation of Art Instruction}

This activity is within standard practices in teacher education of requiring preservice teachers to observe and respond to experienced teaching during field observations (Bellon, Bellon \& Blank, 1992). To

Marilyn Zurmuehlen's Working Papers In Art Education 1994-1995 
understand how student art teachers consider learners' prior knowledge, key concepts, and studio during art instruction, participants were asked to observe a summarized, videotaped unit of actual art instruction.

While watching the video, the nineteen participants were cued to think about and respond only to the variable in this study - learner's prior knowledge, and key concepts in lesson planning. For consistency, all participants observed the same videotape of art instruction.

In order to provide the same teaching scenarios from which participants could make observations and comments, a summarized, videotaped unit of art instruction was produced. Several experienced art leachers were initially observed to determine whose teaching-learning activities best demonstrated observable connections between learningteaching theories and practice. The sequential teaching of key concepts, the consideration of students' prior knowledge in lesson planning and implementation, and studio activities that reinforced lesson content were other criteria in the selection of which teacher to videotape.

The eiementary art teacher selected for videotaping has taught art for twenty-six years. She planned a summer visual art program for fourth and fifth graders. The theme for the eight session, eighteen hours of art instruction was "Stories and Storytellers in Art." This summer program provided the content for the videotaped unit of art instruction. Each of the eight sessions were videotaped. While editing the eighteen hours of art instruction, it became necessary to establish face and content validity of the summarized version of the art instruction - so as not to misrepresent what actually happened for the purposes of this study. Therefore, a rough prototype of the proposed final video was sent to three expert judges whose research interest is in teacher education and higher-order teaching and learning. They were asked to evaluate the prototype video and participant response booklets, and to consider the learners' prior knowledge and the key concepts in the video. General suggestions which might improve the sequence and content of the video and participant response booklet were also sought. A few minor changes were made as a result of these face and content validity determinations. A thirty-four minute video was the result of this collaboration. The videotape was edited in a professional facility.

During the Student Teaching SeminarNorkshop, a prepared protocol instructed participants to observe the videotaped art lessons and respond in written form in their participant booklet. A field test and two pilot tests with the videos and participant response booklets were accomplished 
with art education majors prior to performing this study. There was

an $\mathrm{A}$ component and a $\mathrm{B}$ component in the data collected during this activity.

A ten minute break took place between interventions one and two. There was a table of snacks: participants had been advised at the beginning of the workshop that they would not be able to leave the classroom during the workshop.

\section{Activity Two: Participant Observation of Teacher interview}

The second activity of the workshop was planned to give the participants an opportunity to listen to an experienced teacher talk about her decision-making process during lesson planning. By listening to the teacher from the first video discuss what she considered to be the leamers' prior knowledge and the key concepts in each lesson, participants had a perspective in addition to their own to ponder regarding the learners' prior knowledge and the key concepts in the overall unit. There was an A component and a $\mathrm{B}$ component in the data collected during this activity

\section{Activity Three: Direct Instruction on Cognitive Teaching-Learning Research and Art Teaching}

Direct instruction on cognitive learning research was the third activity in this workshop; for when teachers use both practical and research knowledge as the basis for instructional decisions, teaching strategies will be more effective (Bellon, Bellon, \& Blank, 1992, p. 4).

The definitions of terms such as cognitive learning, higher-order thinking, learners' prior knowledge and key concepts were presented. Up until this point, learners' prior knowledge and key concepts had been explained only with a contextual statement about their educational importance in higher-order teaching-learning. (The statements prefaced participant observation questions in the participant response booklets). The purpose of not defining the terms earlier in the study was to ascertain the preservice teachers' understanding of these terms as baseline data before the direct instruction.

During the direct instruction, overhead transparencies were used as teaching aids, and segments from the first video were shown as examples of research theories being put into practice. The following segments provided real-life examples/non-examples of cognitive instruction:

- the teacher attempting to assess the learners' prior knowledge 
- the teacher bridging the learners' prior knowledge and new lesson content using critical inquiry

- the teacher attempting to clarify possible misconceptions in the young learners' prior knowledge

- the teacher using a key concept in two different lessons--same big idea, different artists and artworks as illustrations of the key concept

- the teacher using a familiar analogy from the learners' prior knowledge to illustrate a key concept about the theme of storytelling

Two brief background questionnaires were completed at the conclusion of the workshop in order to gain information about the participants' art training and teaching and studio experience.

\section{Phase Three: Lesson Plan Re-Critique}

The third and last phase of the study focused on the student teachers' new comprehension and reflection. The participants were asked to re-critique their original lesson plan. As in phase one, they were cued to reflect on their decision-making regarding the learners' prior knowledge, key concepts, and the use of studio in their lesson planning.

\section{Phase Three: Follow-up Interview}

A follow-up thirty minute semi-structured interview occurred with iwelve of the nineteen participants to conclude this third and final phase of the study. The twelve participants volunteered for this activity as it was not required in the seminar's coursework. These audio-taped interviews were designed to examine the reflections of preservice art teachers on learners' prior knowledge and key concepts in lesson planning. These interviews were also planned to infer how transfer from the teacher's knowledge base affects lesson content, implementation, assessment and reflection. Openended questions were asked about teaching experience, lesson planning experience, the use of artworks in teaching and studio experience.

If there were questions about any of the participant's responses from phases one or two, an attempt was made to clarify the responses at this time. Participants were asked to explain their selection of key concepts and artworks for lesson content, and the methods they used to "connect" these 
ideas with prior knowledge and existing curriculum. They also explained the way in which studio functions in their lesson planning.

in conclusion, each participant was asked to respond to the statement "After reflecting on the workshop on higher-order thinking, how do you now consider higher-order thinking and learning in your own lesson planning?"

\section{Data Analysis}

The study is inferential in nature, with the purpose of generalizing to a theoretical framework about the acquisition, development, and utilization of preservice art teachers' pedagogical content knowledge. Studies of this nature do not propose to generalize to populations or universes, but to expand and generalize theories (Yin, 1984, p. 25). Published strategies for analyzing qualitative data (i.e., Lincoln \& Guba, 1985; Merriam, 1988) will be implemented. Novice teacher characteristics (i.e., Glaser \& Chi, 1988; Grossman, Wilson, \& Shulman, 1989; Koroscik. 1990) will also be considered.

Categories, processes, and models from general learning research will be further identified and applied to the domain of art education. The two main variables will be investigated from the following written data:

1. lesson plans

2. lesson plan critiques

3. lesson plan re-critiques

4. participants' responses to observations of actual teaching

5. participants' reflections from listening to an experienced art teacher's explanations of her lesson planning

6. participants' new comprehensions (i.e., follow-up interviews)

7. background information from participant questionnaires

\section{Expected Findings}

It is expected that general pedagogical knowledge and subject matter knowledge will affect the content and process of instruction by

Marilyn Zurmuehlen's Working Papers In Art Education 1994-1995 
preservice art teachers. These knowledges affect what and how they decide to teach. It is predicted that teachers with shallow subject matter knowledge will select key concepts that are not central to the field of art. Such concepts regarding artists might give little indication of how that artist has been influenced by earlier artists, by artists from other cultures, or by the beliefs and values of her/his time and place in history. Consequently, it is likely that learners would not have opportunities to make connections between artists, artforms, the study of history and cultures through art, and personal art making. The representation of key ideas in the form of artworks would also be constrained due to the teacher's shallow understanding of the world of art. The use of comparative exemplars and critical inquiry might be bounded by the teacher's inability to select artworks that represent a variety of artforms, different levels of abstraction and more than one culture and/or historical period.

If preservice art teachers do not recognize the importance of considering learners' prior knowledge in lesson planning, their lessons will lack connections and relevance between the learners' prior knowledge and new information. Such unrelated content will not likely provide motivations/strategies to access previously leamed information and transfer it to the new lesson. In addition, the misconceptions within a learner's prior knowledge might not be addressed.

Certainly an art teachers' studio experience is predicted to influence the range of studio activities they select to teach their students. Limited studio experience in two-dimensional and threo-dimensional art making could cause inexperienced teachers to focus on either two-dimensional or threedimensional art making. The way in which art teachers understand the function of studio in art instruction causes them to use it as reinforcement of lesson content or perhaps as a separate art making activity.

It is predicted that the intervention activities in this study will elicit teacher reflection and new comprehension about research on teachinglearning and lesson planning.

\section{Significance of the Study}

This study is important to the field of art education for several reasons. This study isolates and investigates the pedagogical content knowledge that tomorrow's art teachers bring to lesson planning and art instruction. The fact that it holds the possibility for being the first of a series of studies by this researcher about art teachers' acquisition, development, and utilization of pedagogical content knowledge means that an existing gap in 
general education and art education literature might be lessened.

Furthermore, this study gives art education a common language with other domains in education. Most importantly this study will demonstrate that the quality of art teaching is affected by teacher education. By using research variables and questions generated from well-regarded programs such as the Knowledge Growth in Teaching project and the Center for the Learning and Teaching of Elementary Subjects, this study attempts to connect with existing studies that have field and pilot tested similar research questions.

Key ideas are just now being identified in domains such as mathematics (Lampert, 1986) and science (Chi, Feltocich, \& Glaser, 1981; Larkin, 1982). Though it is not likely or desirable that a field such as art education will come to a consensus about all the "big ideas" for instruction, some ideas in a discipline are simply more important than others (Prawat, 1989, p. 6). This study seeks to identify what beginning art teachers consider to be important ideas and concepts for art instruction.

This study will explore how the unique phenomenon of studio functions in art planning and teaching by preservice teachers. Is studio used to reinforce lesson content? The personal reflections of these preservice art teachers upon their own knowledge and experience has relevance to teacher preparation/instruction. Learning through research about preservice art teachers' knowledge and experiences gives us a sneak preview of the art teaching of tomorrow. Regardless of technological advancements in instruction and knowledge acquisition, teachers (including teacher educators) are still at the heart of instruction. Thus, a study such as this on teaching and learning will always be timely. 


\section{References}

Anderson, C. (1988). The Role of Education in the Academic Disciplines in Teacher Preparation. In Woolfolk, A. (Ed.), Research Perspectives on the Graduate Preparation of Teachers (pp. 88-107). New Jersey: Prentice-Hall.

Bellon, J. J., Bellon, E. C., \& Blank, M. A. (1992). Teaching From a Research Knowledge Base. New York: Macmillan.

Dewey, J. (1904/1964). The Relation of Theory to Practice in Education. In R. Archambault (ed.), Dewey on Education. Chicago: University of Chicago Press.

Carnegie Task Force on Teaching as a Profession. (1986). A Nation Prepared: Teachers for the 21st Century. Washington, DC: Carnegie Forum on Education and the Economy.

Chi, M. T. H., Feltovich, P., \& Glaser, R. (1981). Categorization and Representation of Physics Problems by Experts and Novices. Cognitive Science, 5, 121-152.

Elbaz, F. (1983). Teacher Thinking: A Study of Practical Knowledge. New York: Nichols Publishing Company.

Glaser, R., \& Chi, M. T. H. (1988). Overview. In M. T. H. Chi, R. Glaser, \& M. J. Farr (Eds.), The Nature of Expertise (pp. xv-xxviii). Hillsdale, $\mathrm{NJ}$ : Lawrence Erlbaum.

Gudmundsdottir, S. (1987). Pedagogical Content Knowledge: Teachers' Ways of Knowing. Paper presented at the annual meeting of the American Educational Research Association. New Orleans.

Grossman, P. L., Wilson, S. M., \& Shuiman, L. S. (1989). Teachers of Substance: Subject Matter Knowledge for Teaching. In M. C. Reynolds (Ed.), Knowledge Base for the Beginning Teacher. (pp. 23-46). Oxford: Pergamon.

Grossman, P. L. (1990). The Making of a Teacher. Teacher Knowledge and Teacher Education. New York: Columbia University, Teachers College Press. 
Holmes Group. (1986). Tomorrow's Teachers: A Report of the Holmes Group.

Howsam, R. B., Corrigan, D. C., Denemark, G. W., \& Nash, R. J. (1976). Educating a Profession. Washington, DC: American Association of Colleges for Teacher Education.

Koroscik, J. S. (1990). Novice-expert Differences in Understanding and Misunderstanding Art and Their Implications for Student Assessment in Art Education. Paper presented at the annual meeting of the American Educational Research Association, Boston.

Koroscik, J. S. (1992). Assessing Student Learning in the Visual Arts: Application of a Theoretical Model. Paper presented at the annual meeting of the American Educational Research Association, San Francisco.

Lampert, M. (1986). Knowing, Doing, and Teaching Multiplication. Cognition and Instruction, 3, 305-342.

Larkin, J. H. (1982). The Cognition of Learning Physics. American Journal of Physics, 49, 534-541.

Leinhardt, G. \& Smith, D. (1985). Expertise in Mathematica Instruction: Subject Matter Knowledge. Journal of Educational Psychology, 77 (3), 247-271.

Lewis, A. \& Smith, D. (1993). Defining Higher Order Thinking. Theory Into Practice, 32 (3), Summer, 131-137. College of Education, The Ohio State University.

Lincoln, Y. S. \& Guba, E. G. (1985). Naturalistic Inquiry. Newbury Park, CA: Sage.

Merriam, S. B. (1988). Case Study Research in Education: A Qualitative Approach. San Francisco: Jossey-Bass.

The National Endowment for the Arts. (1988). Toward Civilization: A Report on Arts Education. Washington, C. C.: Author.

Porter, A. C., \& Brophy, J. (1988). Synthesis of Research on Good Teaching: Insights From the Work of the Institute for Research on Teaching. Educational Leadership, 45 (8), 74-85. 
Prawat, R. (1989). Promoting Access to Knowledge, Strategy, and Disposition in Students: A Research Synthesis. Review of Educational Research, $59(1), 1-41$.

Reynolds, M. C. \& Strom, S. M. (1988). Knowledge Bases for the Beginning Teacher. Paper presented at the February 20 Annual Meeting of the American Association for Colleges of Teacher Education, New Orleans, Louisiana.

Shulman, L. S. (1986). Those Who Understand: Knowledge Growth in Teaching. Educational Researcher, $15(2)$, 4-14.

Shulman, L. S. (1987). Knowledge and Teaching: Foundations of the New Reform. Harvard Educational Review, 57(1), 1-22.

Shulman, L. S. \& Sykes, G. (1986). A National Board for Teaching? In Search of a Bold Standard: A Report for the Task Force on Teaching as a Profession. New York: Camegie Corporation. p. 6.

Wilson, S. M., Shulman, L. S. \& Richert, A. E. (1987). 150 Different Ways of Knowing: Representations of Knowledge in Teaching. In J. Calderhead (Ed.), Exploring Teachers' Thinking (pp.104-124). London: Cassess.

Wilson, S. M. \& Wineburg, S. S. (1988) Peering at History Through Different Lenses: The Role of Disciplinary Perspectives in Teaching History. Teachers College Record, 89 (4), 524-539.

Yin, R. K. (1984). Case Study Research. Newbury Park, CA: Sage Publications, Inc.. 